\title{
Perceptions of Collaborative Learning in Enhancing Undergraduate Education Students’ Engagement in Teaching and Learning English*
}

\author{
Queenie P. S. Law, Joanne W. Y. Chung, Lawrence C. C. Leung \\ The Education University of Hong Kong, New Territories, Hong Kong \\ Thomas K. S. Wong \\ Guangzhou Medical University, Guangzhou, China
}

\begin{abstract}
In literature, student engagement was discussed in terms of behavioral engagement, cognitive engagement, and motivational engagement. If students are engaged, they demonstrate their effort, persistence, and instrumental help-seeking behaviors. The purpose of this study was to gain a deeper understanding of the collaborative learning that influence or contribute to engagement in learning among education students. A qualitative descriptive approach was adopted to explore the perceptions of engagement among the selected education students. In the study, semi-structured interviews were conducted. Using thematic analysis techniques, the transcribed interview data were coded, categorized, and analyzed. They were put into five major themes: (a) effort and commitment; (b) teaching strategies used; (c) interest enhancement; (d) positive impacts; and (e) positive attitudes. This study found out that the education students' engagement in teaching, learning English could be enhanced through collaborative learning, and their divergence in engagement can be topics for further research.
\end{abstract}

Keywords: engagement, collaborative learning, undergraduates, educational research, English language teaching

\section{Introduction}

Academic engagement has three constructs which are behavioral, cognitive, and motivational engagement (Linnenbrink \& Pintrich, 2003). Other authors defined engagement in a multifaceted manner as behavioral engagement, emotional engagement, and cognitive engagement (Fredricks, Blumenfeld, \& Paris, 2004; Skinner \& Belmont, 1993).

Behavioral engagement, as stated by Fredricks et al. (2004), contributed to positive learning. It includes students' willingness to make efforts, persistence to academic tasks, attention in class, and involvement in class discussions. In addition, participation in school-related activities was considered as important in behavioral engagement. As Linnenbrink and Pintrich (2003) pointed out, behavioral engagement involved some

\footnotetext{
* Acknowledgement: We would like to acknowledge the help and support from the education students from the University. In particular, we would also like to thank teachers and principals of the secondary school for their support and involvement that made this study possible.

Queenie P. S. Law, M.Sc., lecturer, Department of Health and Physical Education, The Education University of Hong Kong. Joanne W. Y. Chung, Ph.D., professor, Department of Health and Physical Education, The Education University of Hong Kong. Lawrence C. C. Leung, Ph.D., professor, Department of Cultural and Creative Arts, The Education University of Hong Kong. Thomas K. S. Wong, Ph.D., distinguished professor, Guangzhou University of Chinese Medicine, Guangzhou Medical University.
} 
observable behaviors. Students were more engaged when they showed more effort, persistence to the tasks, and help-seeking behavior. Sometimes, the help-seeking behavior alone is not a good indicator of behavioral engagement. If students are seeking help from peers or teachers in order to understand better, this is a good indicator of help-seeking behavior. Also, students are said to be engaged when they show positive behaviors, such as increasing class participation and attendance; and reinforcing task completion and effort (Fredricks et al., 2011; Miller, Greene, Montalvo, Ravindran, \& Nichols, 1996).

As for cognitive engagement, Fredricks and his colleagues (2011) summed it up into two themes: (1) as an investment of time in thinking about learning; and (2) as developing learning experiences using strategic skills. When students are cognitively engaged, they demonstrate the use of metacognitive strategies to plan, monitor, or evaluate their learning (Pintrich \& De Groot, 1990; Zimmerman, 1990). Therefore, students who are cognitively engaged display a deeper level of learning by paraphrasing or summarizing materials or organizing knowledge with concept maps or outlines. Students demonstrate effort in tasks when they are being engaged cognitively in monitoring and regulating their learning by reflecting on their own thinking, actions, and behavior (Linnenbrink \& Pintrich, 2003).

\section{Literature Review}

According to Fredricks and his colleagues (2004), emotional engagement refers to students' positive and negative affective reactions towards teachers, peers, and content of the subjects in schools. The positive affective reaction includes feeling interest, optimism, passion, and curiosity to learn. The negative affective reaction includes feeling boredom, unhappiness, and anxiety in learning (Skinner \& Belmont, 1993). Motivational engagement from Linnenbrink and Pintrich (2003) stated similar characteristics in terms of students' interest, value, and affect.

Interest is a motivational variable and is defined as a psychological state of mind to engage, be engaging, or participate with specific classes of objects, events, or ideas over a period of time. The affective component of interest refers to positive emotions accompanying engagement (Hidi \& Renninger, 2006) and people who feel interest in an activity are more engaged in it. This is supported by Ainley, Hidi, and Berndorff's (2002) study which suggested that interest was an important component in engagement. Since engagement is associated with positive affect, people like performing a certain task feel more interest, and then they are more persistent with the task and they tend to learn more.

Eccles and his colleagues (1983) studied task values in motivational literature and elaborated that task values had four major components which were known as attainment value or importance, intrinsic or interest value, utility value or usefulness of the task and cost. Attainment value refers to the importance of performing well on the task. Intrinsic or interest value is related to the enjoyment of engaging in the task or activity. Utility value refers to the importance of fulfilling the goal of the task. Cost refers to what people would like to give up doing a task which is the negative aspect of engaging in the activity or task. Both positive and negative affect are linked to students' learning and achievement, and high levels of anxiety will negatively affect learning (Linnenbrink \& Pintrich, 2003). Besides, students' behaviors are also shaped by emotions, which are markers of motivational resources for checking the quality of students' participation and coping or whether students are at risk of burnout (Skinner, Pitzer, \& Brule, 2014).

The question of engaging students actively in class has been discussed for decades in the education field. The answer may be collaborative learning. Collaborative learning is an instruction method in which students 
work in groups and they actively exchange their ideas through the use of small group activities with the goal of completing a specific task. It shifts the responsibility of learning to students who take up the role of self-directed learners. Collaborative learning activities have different varieties, but the most vital is exploring or applying the course material, not just simply presentation or explication by students (Smith \& MacGregor, 1992). Collaborative learning gives students an opportunity to engage in discussions and take responsibility of their own learning. Therefore, collaborative learning is good for the new generation as it contributes to developing positive attitudes among students.

Collaborative learning was rooted in three theoretical frameworks—cognitive development theory, social interdependence theory, and social learning theory.

Cognitive development theory has its origins in Piaget (1995) and Vygotsky (1978). Vygotsky (1978) believed learning was facilitated by interaction between peers, such as verbal discussions and observation of peers. The social interactions let students understand what they observe. Moreover, copying and internalizing help students learn, while Piaget's focus upon the development of cognition was the construction of knowledge. Smith and MacGregor (1992) stated learning was the outcome of social interactions. They developed assumptions about learning: Learning was an active constructive process that depended on rich context. The learners are diverse and inherently social and they have affective and subjective dimensions. Therefore, the paradigm of teaching and learning is shifting away from typical teacher-centered to student-centered in collaborative learning. Collaborative learning is socially and intellectually involving, when students are working in groups of two or more, mutually participating in the process, and working toward goals and finishing tasks.

Social interdependence theory can be traced back to 1900s when Lewin proposed the concepts of positive interdependence, meaning that the chance of attaining one's goal is positively correlated to the chance of others obtaining theirs. In this kind of interdependence, students understand that helping others will also benefit themselves, as they will achieve their goals, too. If students are in such a cooperative relationship with one another, they are more effective in communication and with good attitudes.

Last but not least, social learning theory was developed by Bandura (1971) whose theory postulated learning as a social process that determines the requirements for learning. Through experiencing something by oneself or observing others' behaviors, new behaviors will be acquired. Individuals will learn from one another by observation and reinforcement; and reinforcement is one of the factors that can influence behavior. Subsequently, behavior partly creates the environment and the resultant environment, in turn, influences the behavior. In this two-way causal process, the environment is just as influence able as the behavior it controls.

The aim of this study was to explore education students' perception of engagement in learning via collaborative learning and the research questions of this study were:

1. Does collaborative learning increase students' engagement in teaching and learning English?

2. What are the education students' perceptions of engagement in teaching and learning via collaborative learning?

\section{Methods}

\section{Study Design, Participants, and Setting}

This was a qualitative study to explore education students' perceptions of engagement in teaching and learning via collaborative learning. 


\section{Subjects and Recruitment Procedures}

The education students were recruited by convenience sampling through posting promotional posters in the intranets of the Education University of Hong Kong. The subjects of this study were eight education students.

After recruitment, each education student was assigned to provide English tutorial lessons to secondary school students in a group size of three to four. Either all selected secondary school students were new immigrants from Mainland China or coming from low-income families whose native language was not English. Before starting the tutoring program, English enhancement workshops were provided to the education students. The English enhancement workshops covered core fundamentals and common errors in English as well as some basic teaching skills. Class observation and coaching of the education students were conducted by the English instructor. In the training workshops, the English instructor and the students established learning objectives together and set mutual goals. In the process, the education students were encouraged to submit at least three learning goals, their lesson plans, and reflections before and after class respectively. Subsequent class observations with supportive coaching were done by the English instructor. Each tutorial class with the secondary students was conducted by an education student in a group size of three to four, and met once per week for 20 weeks.

\section{Ethical Consideration}

Approval of the study was obtained from the ethics committee of the university. With assured confidentiality and anonymity, all participants were informed of the purpose and nature of the study before they gave their written consent. They were told that data obtained would solely be used for research purposes, and all raw data would be destroyed after the study was completed.

\section{Data Collection}

A semi-structured focus group interview was conducted to collect the education students' perceptions of engagement in teaching and learning English upon the process of collaborative learning.

\section{Data Analysis Plan}

The semi-structured interview was audio-recorded and transcribed verbatim in Chinese. All the verbatim transcription was then translated into English, which was later coded and used for qualitative thematic analysis as described by Braun and Clarke (2006), to examine the process of collaborative learning and the participants' responses. The process of data analysis of thematic analysis has six steps. A report of the analysis was produced by using NVivo 8.

\section{Result}

\section{Sample Characteristics}

Eight education students were recruited, comprising $75 \%$ male and $25 \%$ female education students. They were all Chinese. With respect to their distribution, 50\% were from undergraduate Year one, 37.5\% were from undergraduate Year two, and one of them (12.5\%) was from undergraduate Year three. The demographic characteristics of the sample were shown in Table 1 below.

\section{Findings}

In the program, collaborative learning was implemented to help improve education students' engagement 
in teaching and learning English. A semi-structured interview was conducted for the students after their completion of all tutoring lessons. A majority of the education students (75\%) finished all 20 of the tutorial lessons. Only two of them could not finish all, because some of their tutorial lessons' time clashed with their field experiences on community services required by their undergraduate programs. For these two students, exit questionnaires instead of the interview were used to collect their feedback about the collaborative learning. The collected feedback data were grouped into themes as elaborated below.

Table 1

Demographic Characteristics of the Sample $(N=8)$

\begin{tabular}{lllc}
\hline \multirow{2}{*}{ Demographic characteristic } & & Number of students and percentage \\
\cline { 3 - 4 } Gender & & No. & Percent (\%) \\
\multirow{2}{*}{ Ethnicity } & Male & 6 & 75.0 \\
& Female & 2 & 25.0 \\
\multirow{2}{*}{ Year of study } & Chinese & 8 & 100.0 \\
& Undergraduate Year one & 4 & 50.0 \\
& Undergraduate Year two & 3 & 37.5 \\
\hline
\end{tabular}

\section{Theme 1: Improvement in English}

During the process, the education students wrote teaching plans, prepared teaching materials, and delivered tutoring lessons to the secondary school students. During the preparation and teaching process, the education students used different strategies for teaching English. After the completion of the program, the education students felt that they were more interested in teaching and learning English. Moreover, their confidence in using English was also enhanced. The sub-themes of this theme will be discussed in more detail in the following sections.

\section{Sub-Theme: Different Strategies for Learning Used}

It was discovered that all education students made an effort to improve their English by using different strategies in learning and teaching. One of them expressed that he discovered the strengths and weaknesses of his/her English during teaching. In the process, he/she tried out different teaching strategies, and had them clarified. Another education student described that he/she discovered his/her English weaknesses during the preparation of his/her teaching materials. This process helped him/her familiarize with English by spotting out his/her common errors in English. In addition, he/she could revise his/her English usage through teaching. One other student mentioned that the program could consolidate his/her foundation in English, because he/she had to find extra supplementary exercises to help his/her students learn grammar and build vocabularies.

Discovered the weaknesses of my English... Improved my familiarity with English... Spotted the common errors in the preparation of teaching... Revised my English usages through teaching... (S1)

Discovered the strengths and weaknesses of English... Clarified my learning strategy... (S2)

Revised and integrated the English usage... Found some useful vocabularies to teach the students... Found extra supplementary grammar exercises for students. (S3)

Moreover, the education students also made use of different strategies for teaching, such as through YouTube videos, movies, and English songs. Besides, some of them selected different teaching materials like games, songs, reference books, etc.. Going through the teaching process, one student was delighted that he could tackle fear in speaking. 
Using Pictionary to teach English... Searched for exercises in libraries... Screened and selected different suitable supplementary exercises... Tackled fear in speaking. (S4)

Tried to use different strategies to learn English, e.g., YouTube videos, movies, and TV shows. (S5)

Tried to use different strategies to learn English, e.g., English songs. (S6)

Sub-theme: Increased interest in learning English.

Nearly all education students showed more interest in teaching and learning English, with the exception of two students—one indicated the program had little impact on him and the other indicated that her interest was maintained.

More interested in English. (S1)

Took initiative and interest in teaching and learning English. (S2)

Maintained interest in English. (S3)

More interested in English. (S4)

Little impact on my interest in teaching and learning English. (S5)

Enhanced my interest in teaching and learning English. (S6)

Sub-theme: Growth in confidence.

A majority of the education students became more confident in using English after the collaborative learning session. Although one student commented that there was little impact on his confidence in English, he expressed there was a positive impact that enhanced his speaking ability.

Found ways to explain it clearer... Enhanced my English...Enhanced my speaking ability... Enhanced my confidence. (S1) Gained confidence in teaching English... Enhanced confidence in English especially in speaking and writing. (S2)

My confidence in English language skills was greatly enhanced. (S3)

Boosted my confidence... Managed to use English language as a medium of instruction... Improvement in speaking... Gained confidence in teaching English. (S4)

Positive impact, enhanced in speaking ability... Little impact on my confidence in teaching and learning English. (S5)

Enhanced my confidence in teaching and learning English. (S6)

One student ascribed the increase in his confidence to the program, because he/she managed to use English language as a medium of instruction in the tutoring lessons. During sharing, one student reported he/she had improvement in speaking, which in turn enhanced his/her confidence in English. The education students perceived an improvement in English in terms of "felt more confident in English," "different strategies for teaching and learning used," and "more interested in teaching and learning English.” The above students' judgments about their capabilities in English were important in showing their enhancement of self-efficacy. All education students indicated their improvement through the preparation of teaching materials and delivery of tutorial lessons.

\section{Theme 2: Gained Varied Skills}

Apart from the improvement in English, the education students gained varied skills during the process. Especially during the teaching process, they had to organize their teaching materials and to interact with their students. Through these processes, they said that they had gained teaching and interpersonal skills. The sub-themes will be discussed in more detail in the upcoming sections.

\section{Sub-Theme: Teaching Skills}

The education students gained teaching skills via collaborative learning and some of them even gained confidence in teaching. 
Gained teaching experience... Gained the ability to manage a lesson... Gained implementation skills... Gained confidence in teaching English. (S4)

Gained interest and confidence in teaching English. (S2)

Strengthen the foundation in teaching skills. (S1)

All tutors tailored their teaching with different strategies and engaged in post-teaching reflection. They supplemented their teaching with various resources, which increased the secondary school students' interest of learning. In addition, the lessons were more interactive, because the education students had developed self-confidence in speaking, while the secondary school students were more willing to give feedback. Besides textbook exercises, the education students arranged a variety of activities to arouse the secondary school students' interest. Activities, such as playing games, watching movies or YouTube videos, reading newspaper articles, doing exercises, finding reference books, etc., were some of the ways to motivate the secondary school students to apply knowledge and skills, even when at home. Moreover, the secondary school students were reminded to strengthen their knowledge by recapping and revision.

Screened several supplementary exercises and used them as teaching materials... Using music video... Scrabble... Games to teach English... (S1)

Found some useful vocabularies to teach the students... Found extra supplementary exercises for students to hone their skills in grammar... (S3)

Found reading passages via resources... Found some English songs to train their listening skills... (S2)

Searched for exercises in library... Reinforced their skills before the school examination... Broke up the lesson into small parts for recapping and teaching. (S4)

Found good textbooks and exercises for the lessons. (S5)

Used reference books to prepare the lessons. (S6)

In order to strengthen the secondary school students' learning ability in English, the tutors used an all-round method to teach English, including reading, writing, listening, and speaking. They discovered that the secondary school students in general lacked confidence in speaking English, especially during self-introduction, self-reflection, and opinion sharing sessions. Two education students mentioned they assessed students' ability at the beginning so that they could teach the students according to their standards and needs.

Taught students with reference to their weaknesses... Assessed students' ability at the beginning to understand their needs... Tried to find ways to explain it directly and easily. (S2)

Bought teaching materials for students... Prepared a mini test for assessing the students’ levels... (S3)

Some education students tried to inspire their students with their personal experiences and previous teaching experiences.

\footnotetext{
Inspired students by using my personal experiences. (S3)

Used previous teaching experience to prepare the lessons. (S6)

Shared my own perception to stimulate students' interest in learning English. (S1)
}

Some education students were committed to their teaching even though they faced difficulties in dealing with students' differences in standards and levels. Some went as far as complaining about insufficient teaching resources, etc., and tried solving these problems by investing more time and effort in the preparation for the lessons. 
Due to difficulty in searching for resources that fit the students' levels, I used more time in designing the question paper... Tried to find ways to explain it directly and easily... (S2)

Difficulty in finding teaching resources at the beginning... Referring to other textbooks when I came across unfamiliar situations... After I had got the resources, the teaching became smooth and easy... (S3)

Difficulty in following the teaching plan in real life... It was necessary to be well-planned and prepared for alternatives... The most difficult part was dealing with individual differences of students... It was a common problem in teaching... Adjustment of the teaching materials to suit the level of students... Invited students with better skills to help other students. (S1)

Faced the problem of individual differences amongst students... Taught from simplicity to complexity to stimulate students' interest... Invited students with better skills to help other students... (S4)

Besides, the education students exerted effort to improve their teaching by performing reflections. Most of them did reflections after teaching. Some of them evaluated their teaching for improvement by seeking students' feedback after lessons.

Did reflection in teaching... Did reflection on my suitability as a teacher. (S2)

Evaluated my teaching via students' feedback... Did reflection in teaching... Found ways to improve. (S1)

Seek students' feedback in every lesson for evaluation. (S4)

Did reflection in teaching. (S3)

Furthermore, the education students wrote teaching reflections after each lesson and graded themselves in a scale of " 1 " to "10," with "10" being the best. They ranked themselves at an average of "7" in teaching performance in the tutoring lessons. They were confused at the beginning due to the lack of experience in teaching, arranging in-class activities, and leading students to response in lessons. In general, their scores went up from "6" to " 8 " after sometime when they became more experienced in lesson handling and seeking students' feedback.

\section{Sub-Theme: Interpersonal Skills}

On top of gaining teaching skills, the education students also acquired interpersonal skills, which are essential for the successful career of a student. As this teaching experience included opportunities to communicate with the secondary school students, they learnt new communication skills when interacting with their students. Being student teachers, they learnt how to think from teachers' and students' perspectives. These were valuable interpersonal skills gained from their teaching, via communicating and building good relationships with their students.

Learnt how to interact with students... Learnt the skills in dealing with students with individual differences. (S5)

Gained different perspectives as a teacher. (S1)

Increased the confidence in interpersonal skills... (S3)

Gained communication skills with students. (S2 and S4)

Gained ways to help students to have satisfactory development... To see things from students' perspectives. (S2)

Some education students built good relationships with their students.

Building up trust with students is important. (S3)

Gained adaptability... Built up trust with students. (S4)

Achieved in building students' trust... Gained people skills. (S2)

One education student gained skills in time management. She stated that, "She gained time management skills," after participating in the collaborative learning process. 


\section{Theme 3: Positive Attitude}

Without positive attitudes, students found it difficult to learn proficiently. The education students were satisfied with the program and displayed positive learning attitudes after participation.

Satisfied with the teaching... Students were very attentive in lessons, took initiative to ask questions... A good learning atmosphere. (S5)

The sub-themes related to this theme are discussed below.

\section{Sub-Theme: Developed a Positive Learning Attitude}

The education students developed a positive learning attitude after participation in the program, which included enjoying their work and getting positive impact from the job. Also, they demonstrated effort and commitment in teaching. One education student was pleased with her teaching because her students had gained confidence in learning English.

Am pleased because my students have gained confidence in learning English... Overall, I am satisfied with my teaching... Reflect that my students have gained confidence in using English. (S4)

All education students thought this collaborative learning program had positive impact. Two of them mentioned that this project was meaningful as it promoted mutual help. In addition, most of them thought that this teaching experience might help their future teaching career by enriching their teaching skills.

Does enrich my teaching skills... A lot of benefits. (S1)

A big positive impact on me... Helpful to my career path. (S2)

Gained teaching experience... Good for my teaching career in the future... Helpful to my career path. (S4)

Positive impact. (S3)

Positive impact on my career... It is a good experience to contribute to the community, especially to help the disadvantaged groups. (S5)

This project is meaningful to help the students with low proficiency in English... Positive impact on my career. (S6)

All education students demonstrated behavioral engagement, showing great effort and commitment in teaching. They used a lot of time in preparing the teaching materials, designing appropriate question papers to suit their students' needs. Moreover, they put in a lot of effort in teaching. For example, they had great patience in getting answers from their students and used many different ways to explain the answers clearly for difficult questions. They also showed passion in teaching as they tried very hard to boost students' confidence in learning English.

Used a lot of time to explain the answers... Allowed adequate time for students to find answers... Helped them overcome the fear in using English... Helped them boost their self-confidence through activities... Spent more time in designing question papers for students... Taught students with patience. (S2)

Used a lot of effort to teach... Built up students' confidence in English... Revisited the teaching materials and found lively and vivid ways to present them to attract students... Thought of ways to arouse students' interest. (S3)

Wanted to raise students' confidence in using English.... (S4)

The most difficult part was dealing with the individual differences of the students... Tried to adjust the level of the teaching materials... Invited brighter students to help other students.... (S1)

From the above observations, the education students demonstrated great engagement in learning English through the usage of different strategies in teaching, demonstration of positive attitudes, expression of interest in English, and display of effort and commitment. 


\section{Discussion}

An end-of-program semi-structured interview and a pre-post instrument were conducted to explore the effect of the collaborative learning on learning engagement. The education students attributed the following to the enhancement of their engagement in learning English: the effort and commitment, different strategies for teaching used, raising interest, positive impact, and positive attitudes in the main themes and their respective sub-themes.

Consistent findings were reported in a large body of literature, e.g., Linnenbrink and Pintrich (2003) stated that behavioral engagement was outwardly observable via behaviors. Students are said to be more engaged when they show more effort, persistence to tasks and help-seeking behaviors. Other positive engagement behaviors are lesson participation, attendance, task completion, and effort (Fredricks et al., 2011; Linnenbrink \& Pintrich, 2003; Miller et al., 1996). All education students showed behaviors in engagement by demonstrating effort and commitment in teaching. They used plenty of time in preparing the teaching materials, designing the appropriate question papers to suit their students' needs. Furthermore, they used a lot of effort in teaching and experimenting with teaching.

Some researchers highlighted student engagement as characterized by a willingness to invest effort in one's work and be persistent even when encountering difficulties (Sanchez-Cardona et al., 2012). Nearly all education students finished their 20 tutoring lessons. Moreover, they showed patience in teaching and used different ways to explain the answers clearly and patiently to their students. In the process, they had to face the problems of individual and level differences of the secondary school students as they came from different backgrounds and different forms. Moreover, some education students faced the problems in finding suitable teaching resources. They had to solve these problems by investing more time in preparing and finding alternative ways. This result showed that they demonstrated behavioral engagement in this collaborative learning program.

Fredricks and his colleagues opined that cognitive engagement is related to "psychological investment in learning" and "strategic learning" (Fredricks et al., 2004, p. 65). When students are cognitively engaged, they demonstrate the use of meta-cognitive strategies and quality effort in tasks. Moreover, students are cognitively engaged if they monitor and regulate their learning by reflecting on own thinking, actions and behavior (Linnenbrink \& Pintrich, 2003). Findings of this study demonstrated that the education students displayed behaviors of cognitive engagement, because they showed initiative in improving their teaching by performing reflections after teaching. Most of them did the teaching reflections soon after each lesson in writing. They evaluated their teaching by asking for student feedback after lessons and found ways to make improvements afterwards. Crucially, these behaviors demonstrated their cognitive engagement and use of meta-cognitive strategies.

Motivational engagement from Linnenbrink and Pintrich (2003) stated similar concepts on students' interest, value, and affect. The result of this study is consistent with previous literatures. Nearly all of the education students showed increased interest in teaching and learning English with the exception of two students-one indicated that the collaborative learning had little impact on his interest in teaching and learning English and the other indicated that her interest in English was the same as before. She went on to explain that she always had a good interest in English and that was why her interest was unchanged. As the affective component of interest is the positive emotions accompanying engagement (Hidi \& Renninger, 2006, p. 112), people feeling interested in the activities are more engaged. Moreover, Ainley et al.’s study (2002) suggested that interest was an important 
component in engagement. Here, engagement was obvious, because the education students showed interest and passion in teaching as they tried to boost their students' confidence in learning English and practiced their teaching using different strategies and performing reflections afterwards.

All education students thought that they had developed multiple task values. They said they had positive gains from this collaborative learning program and mentioned that this project was meaningful, because they had helped others. In addition, most of them recognized that this teaching experience might help their future teaching career by building up a good foundation in teaching. On top of their teaching, they also thought that they gained other skills, such as time management and interpersonal skills. Most of them learnt how to interact and communicate effectively with their students, and they learnt how to think from others' perspectives in the process. After the program, they said they had developed better interpersonal skills.

Positive emotions were displayed in the program. One student demonstrated markers of motivational resources when she was quoted as saying

Felt happy because my students become confident in learning English... I am satisfied with my teaching... Reflected on building up students' confidence in English. (S4)

Besides, good relationships were identified within the groups as one student reported that he was satisfied with the friendship he developed with his students. All these findings supported that the education students demonstrated motivational engagement behavior in this collaborative learning project.

On the downside, there were limitations of this study that deserve mentioning. The sample size of eight participants was relatively small and there was an uneven gender representation, so a rich description of female's perspectives was not generated. In addition, two participants in this study did not turn up for the interview. We cannot rule out that their contribution, if reported, could have broadened the discussion and influenced our results.

\section{Conclusion}

Collaborative learning may enhance students' engagement in learning. The findings supported that most education students perceived enhancement of engagement in learning via participation in this collaborative learning program. In the process, they demonstrated a high level of behavioral, cognitive, and motivational engagement in teaching and learning English when they used different strategies in teaching, demonstrated positive attitudes, showed interest in English, and showed effort and commitment. From these findings, further research should address the divergence in engagement development of students in collaborative learning and investigate different methods to increase possibilities of knowledge acquisition, gain collaborative learning experiences, and incorporate values in self-development. Furthermore, future research should address collaborative learning programs and initiatives designed to increase engagement in learning among students.

\section{Authors' Contributions}

Queenie Law (QL) participated in designing the study, conducting all focus group interviews, and transcribing the interviews, analysis, and drafted the manuscript. All authors participated in developing the final manuscript.

\section{References}

Ainley, M., Hidi, S., \& Berndorff, D. (2002). Interest, learning, and the psychological processes that mediate their relationship. Journal of Educational Psychology, 94(3), 545-561. doi:10.1037/0022-0663.94.3.545 
Bandura, A. (1971). Social learning theory. New York: General Learning Press.

Bandura, A. (1977). Self-efficacy: Toward a unifying theory of behavioral change. Psychological Review, 84(2), 191-215.

Bandura, A. (1986). Social foundations of thought and action: A social cognitive theory. Michigan: Prentice-Hall.

Bandura, A. (1988). Organisation applications of social cognitive theory. Australian Journal of Management, 13(2), $275-302$.

Bandura, A. (1993). Perceived self-efficacy in cognitive development and functioning. Educational Psychologist, $28,117-148$.

Bandura, A. (1995). Self-efficacy in changing societies. New York: Cambridge University Press.

Bandura, A. (1997). Self-efficacy: The exercise of control. New York: Worth Publishers.

Bandura, A. (1999). Self-efficacy: Toward a unifying theory of behavioral change. In R. F. Baumeister (Ed.), The self in social psychology: Key readings in social psychology (pp. 285-298). Philadelphia: Psychology Press/Taylor \& Francis.

Bandura, A. (2006). Guide for constructing self-efficacy scales. In F. Pajares \& T. Urdan (Eds.), Self-efficacy beliefs of adolescents (pp. 307-337). Greenwich, C.T.: Information Age Publishing.

Bandura, A. (2012). On the functional properties of perceived self-efficacy revisited. Journal of Management, 38(1), 9-44. doi:10.1177/0149206311410606

Braun, V., \& Clarke, V. (2006). Using thematic analysis in psychology. Qualitative Research in Psychology, 3(2), 77-101. I

Eccles, J. S., Adler, T. E., Futterman, R., Goff, S. B., Kaczala, C. M., Meece, J. L., \& Midgley, C. (1983). Expectancies, values, and academic behaviors. In J. T. Spence (Ed.), Achievement and achievement motivation (pp. 76-146). San Francisco: W.H. Freeman and Company. doi:10.1207/s15327752jpa8502

Eccles, J. S., \& Wigfield, A. (2002). Motivational beliefs, values, and goals. Annual Review of Psychology, 53(1), $109-132$.

Fredricks, J. A., Blumenfeld, P. C., \& Paris, A. H. (2004). School engagement: Potential of the concept, state of the evidence. Review of Educational Research, 74(1), 59-109.

Fredricks, J., McColskey, W., Meli, J., Mordica, J., Montrosse, B., \& Mooney, K. (2011). Measuring student engagement in upper elementary through high school: A description of 21 instruments. Issues and Answers Report, 98, 26-27.

Hidi, S., \& Renninger, K. A. (2006). The four-phase model of interest development. Educational Psychologist, 41(2), 111-127. doi:10.1207/s15326985ep4102_4

Linnenbrink, E. A., \& Pintrich, P. R. (2003). The role of self-efficacy beliefs in student engagement and learning. Reading \& Writing Quarterly: Overcoming Learning Difficulties, 19(2), 119-137. doi:http://dx.doi.org/10.1080/10573560308223

Miller, R. B., Greene, B. A., Montalvo, G. P., Ravindran, B., \& Nichols, J. D. (1996). Engagement in academic work: The role of learning goals, future consequences, pleasing others. Contemporary Educational Psychology, 21(4), $388-422$. doi:10.1006/ceps.1996.0028

Piaget, J. (1995). Sociological studies. London and New York: Taylor \& Francis Group.

Pintrich, P. R., \& De Groot, E. V. (1990). Motivational and self-regulated learning components of classroom academic performance. Journal of Educational Psychology, 82(1), 33-40. doi:10.1037/0022-0663.82.1.33

Sanchez-Cardona, I., Rodriguez-Montalbán, R., Acevedo-Sotob, E., Nieves-Lugo, K., Torres-Oquendo, F., \& Toro-Alfonso, J. (2012). Self-efficacy and openness to experience as antecedent of study engagement: An exploratory analysis. Procedia-Social and Behavioral Sciences, 46, 2163-2167. doi:10.1016/j.sbspro.2012.05.446

Skinner, E. A., \& Belmont, M. J. (1993). Motivation in the classroom: Reciprocal effects of teacher behavior and student engagement across the school year. Journal of Educational Psychology, 85(4), 571-581.

Skinner, E. A., Pitzer, J. R., \& Brule, H. A. (2014). The role of emotion in engagement, coping, and the development of motivational resilience. In R. Pekrun, \& L. Linnenbrink-Garcia (Eds.), International handbook of emotions and education (pp. 331-347). New York: Taylor \& Francis.

Smith, B. L., \& MacGregor, J. T. (1992). What is collaborative learning? In A. Goodsell, M. Maher, V. Tinto, B. L. Smith, \& J. T. MacGregor (Eds.), Collaborative learning: A sourcebook for higher education (pp. 1-11). Pennsylvania State University; USA, National Center on Postsecondary Teaching, Learning, and Assessment Publishing.

Vygotsky, L. S. (1978). Interaction between learning and development. In Mind and society (pp. 79-91). Cambridgem, M.A.: Harvard University Press.

Zimmerman, B. J., \& Martinez-Pons, M. (1990). Student differences in self-regulated learning: Relating grade, sex, and giftedness to self-efficacy and strategy use. Journal of Educational Psychology, 82(1), 51-59. 